\title{
Management of esophagus perforation as a late term complication of vertebral surgery: case report
}

\begin{abstract}
Esophagus is the organ under risk of complications during many different types of surgical procedures. One of the most common iatrogenic traumas causing esophagus perforation is the cervical vertebrae surgery. Late term pharyngo-esophageal perforation is a rare but mortal complication of this surgery. Because of this reason, it is vital to take out the foreign material and to repair perforation. In this paper, the diagnosis and management period of a patient with esophagus perforation, 7years after the percutaneous anterior discectomy and fusion with titanium cage procedure, due to the instrument placed on cervical vertebra, will be reported.
\end{abstract}

Keywords: anterior cervical vertebrae surgery, esophagus perforation
Volume 3 Issue I - 2015

\author{
Mustafa Sahin, ${ }^{2}$ G Saylam,' Omer Bayir,' Emel \\ Cadalli Tatar,' M Hakan Korkmaz' \\ 'Department of Otolaryngology Head and Neck Surgery, \\ Diskapi Yildirim Beyazit Research Hospital,Turkey \\ 2Department of Otolaryngology Head and Neck Surgery, Adnan \\ Menderes University Medical School,Turkey
}

Correspondence: Mustafa Sahin, Department of

Otolaryngology Head and Neck Surgery, Adnan Menderes

University Medical School, Hilal Mah, 684. Street, I 2/3, 06550,

Ankara,Turkey,Tel +905336545502, Email iskebaha@gmail.com

Received: April 27, 2015 | Published: July 23, 2015

\section{Introduction}

Nowadays, instrumental fixation of traumatic and degenerative cervical vertebrae diseases with anterior approach is a very commonly preferred treatment method. As a result of the migration of the fixation tool, although rare, pharyngo-esophageal perforation may be seen and this condition may cause severe medical morbidities. ${ }^{1}$ In fact, since esophagus perforation due to cervical vertebrae instrumentation is a rare condition with an incidence of ranging between $0.25-1.49 \%$; there is no consensus about the symptoms, diagnostic approaches and management of this complication, yet. ${ }^{2}$ In this paper, we will report the diagnosis and management period of a 56years old woman with esophagus perforation due to the cervical vertebrae instrument, 7years after the percutaneous anterior discectomy and fusion with titanium cage procedure; and by this way we aimed to support the present data about this topic.

\section{Case report}

Fifty six years old female patient was admitted to the hospital with the symptoms of foreign body sensation in the throat, difficulty in swallowing, fever and weakness for about 2 months. Her medical history was unremarkable accept a cervical vertebrae hernia operation that was performed 7years ago. Her complete ear-nose-throat examination revealed nothing positive except a vague precision on neck palpation. Endoscopic larynx examination revealed mobile bilateral vocal folds, salivary accumulation and edema in post-cricoid region. In biochemical analysis; 1 hour sedimentation, C-reactive protein and white blood cell count levels were (47, 29.7 and 10800, respectively) compatible with an infection. In neck computed tomography (CT); at supraglottic level, posterior to the larynx, in perivertebral region, there was a peripherally contrasting hypo-dense lesion with 19x13mm dimensions and at the same level there was a defective appearance on vertebrae corpus with an increase in bone density and in C4-C6 space, focal hyper-intensities that may be related to operation material (Figure 1). Magnetic resonance imaging revealed disk it is at C4-C6 space; focal hypointense appearances at C5-C6 levels on T1 and T2 weighted images (operation material?) and an appearance compatible with the abscess. With these findings surgery under general anesthesia was planned for the patient and then suspension laryngoscopy and pan-endoscopy were performed. During surgery, at the entrance of esophagus, ovoid, smooth-surfaced, hard, greyish colored foreign material protruding to the lumen with an approximate diameter of $2 \mathrm{~cm}$ was observed (Figure 2).

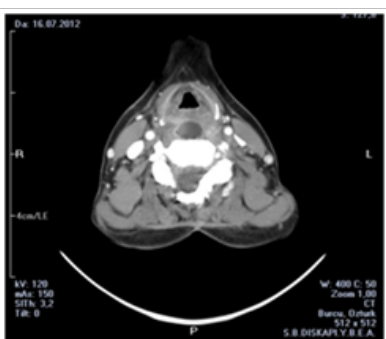

$1 \mathrm{a}$

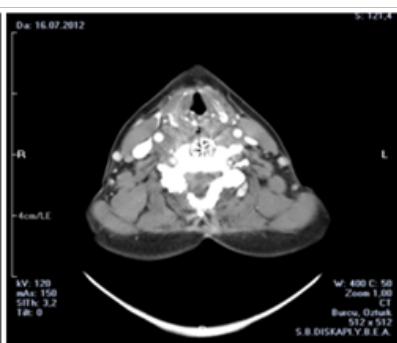

$1 \mathrm{~b}$
Figure I CT images revealed, peripherally contrasting hypo-dense lesion compatible with abscess (a) in the space between larynx and vertebra, and (b) stabilization cage at C4-C6 levels.

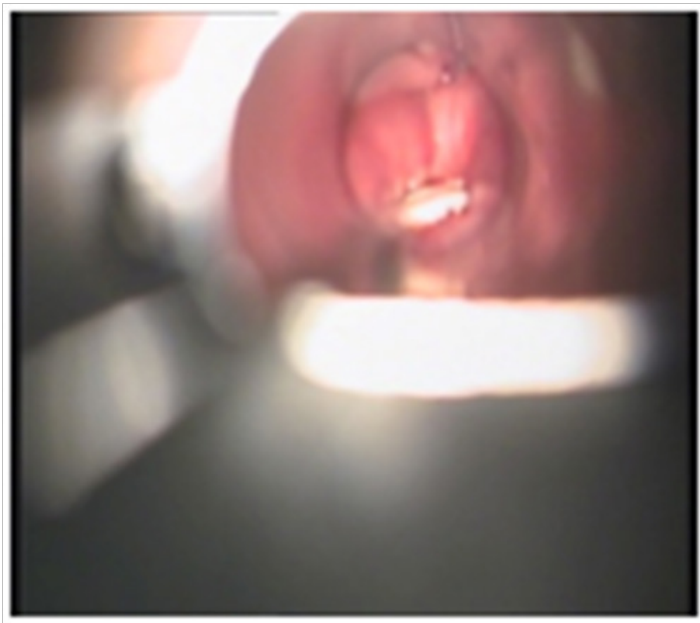

Figure 2 Hard, greyish foreign material, perforating posterior part of the esophagus entrance and protruding through the lumen, determined during esophagoscopy. 
The foreign material was dissected from the neighborhood structures and taken out after debridement of the surrounding granulation and infectious tissues. On the posterior of the foreign material region, abscess was drained, granulation tissues were excised and naso gastric catheter was inserted. On the second day of surgery, enteral nutrition was started and intravenous antibiotic treatment (sulbactam ampicillin, 4x1000mg) started on the first day was continued for 14days. Second surgical intervention was planned for the repair of defective region on esophagus that was left for secondary healing. During the second intervention (approximately 30days after the first one) perforated posterior wall mucosa of esophagus, with a diameter of $2 \times 1 \mathrm{~cm}$ without infective area around, was closed with primary saturation after debridement of the surrounding granulation tissue and naso gastric catheter was re-inserted. One month after the second intervention, since there was not any fistula finding in videofluoroscopic pharyngo-esophagography, naso gastric catheter was exerted and the patient was started to be nourished orally. In 2years follow-up, she is still eating orally without any problems.

\section{Discussion}

Esophagus perforation that can be seen after anterior cervical vertebrae surgeries is a rather rare complication that can cause severe problems. This complication may be seen during surgery or in early postoperative periods as well as months or years later and the subsequent condition is rather rare. ${ }^{3-5}$ As emphasized in this case report, 7years after operation, esophagus perforation may take place due to the migration and protrusion of vertebral stabilization instruments. Chronic pressure ischemia on pharynx and posterior esophagus is also a possible cause.

The symptoms and signs of perforation may vary depending on the reason, localization and timing. Late perforations are more silent compared with the acute perforations and commonly presented with dysphagia, odynophagia, neck pain, abscess on neck region and recurrent aspiration pneumonia. Fever, chest pain and dyspnea may also accompany the picture and it has a large symptom spectrum including sepsis and shock that can result in mortality., ${ }^{5,6}$ In this reported case, dyspnea, odynophagia and fever, weakness and neck pain due to the localized abscess between facial plans for about 2 months were present.

Perforation is generally reported on $\mathrm{C} 4-\mathrm{C} 7$ levels. ${ }^{7}$ The main reason for this may be more common surgical interventions on this region. In this report, the defect causing perforation was on posterior esophagus wall at C4-C6 level. Diagnosis of perforation first starts with the suspicion and then history, general examination and direct graphs are of first priority. In a patient with the history of anterior cervical vertebrae surgery, development of dysphagia and neck abscess requires further investigations for a potential pharyngoesophageal perforation. Plain radiographs may show the presence of pneumo-mediastinum and retropharyngeal-prevertebral air. Other diagnostic methods are esophagus passage graphs with barium, computed tomography, and esophagoscopy. ${ }^{7,8}$ Contrast enhanced esophagography may determine the perforation with an accuracy of higher than $75 \%$. Computed tomography is quite helpful in showing extra-esophageal air and abscess. Posterior pharynx and esophagus may be observed directly with esophagoscopy and it provides $63.9 \%$ correct diagnosis. ${ }^{9}$ In this reported case, during diagnosis, suspected surgery in her history, computed tomography and esophagoscopy findings were helpful.

The main treatment of esophagus perforation is the supported primary repair. If present, the treatment of infection, debridement of necrotizing tissue and nutrition support should be added. ${ }^{1,3,9}$ The treatment of the perforation depends on the severity and penetration of the problem as well as the general health status of the patient. Taking out the protruded free implant material, infection control, and repairing perforation region (primary or if necessary with flaps including local pedicled flaps such as sternocleidomastoid or pectoralis major or radial forearm microvascular free flaps) and completing wound healing, and non-oral nutrition support for at least 4-6 weeks should be included in the treatment plan. ${ }^{5,7-9}$ In this reported case, infection control with the drainage of prevertebral abscess and systemic antibiotics; enteral nutrition support with naso gastric catheter, repair of the perforation with primary saturation after taking out the foreign material were performed and treatment was successful.

\section{Conclusion}

In conclusion, after anterior cervical vertebrae surgeries, though after a long time, it should be kept in mind that persistent dysphagia and odynophagia may be due to the graft material and the history of the patient should be learnt carefully because prompt diagnosis and appropriate management of perforation prevents more severe complications including mortality.

\section{Conflicts of interest}

This study doesn't have any financial support or relationships that may pose potential conflict of interest.

\section{Informed Consent}

Informed consent was obtained from the individual whose special medical condition and data were mentioned in this report.

\section{Funding}

None.

\section{References}

1. Gaudinez RF, English GM, Gebhard JS, et al. Esophageal perforations after anterior cervical surgery. J Spinal Disord. 2000;13(1):77-84.

2. Brinster CJ, Singhal S, Lee L, et al. Evolving options in the management of esophageal perforation. Ann Thorac Surg. 2004;77(4):1475-1483.

3. Younes Z, Johnson DA. The Spectrum of spontaneous and iatrogenic esophageal injury: perforations, mallory-weistears, and hematomas. $J$ Clin Gastroenterol . 1999;29(4):306-317.

4. Patel NP, Wolcott WP, Johnson JP, et al. Esophageal injury associated with anterior cervical spine surgery. Surg Neurol. 2008;69(1):20-24.

5. Korkmaz H, Saylam G, Bayir O, et al.Interscapular pharyngocutaneous fistula: an extreme complication of cervical stabilization surgery. Turk Neurosurg. 2013;23(3):407-409.

6. Zdichavsky M, Blauth M, Bosch U, et al. Late esophageal perforation complicating anterior cervical plate fixation in ankylosingspondylitis: a case report andr eview of the literature. Arch Orthop Trauma Surg. 2004;124(5):349-353.

7. Phommachanh V, Patil YJ, McCaffrey TV, et al. Otolaryngologic management of delayed pharyngoesophageal perforation following anteriorcervical spine surgery. Laryngoscope. 2010;120(5):930-936.

8. Vrouenraets BC, Been HD, Brouwer-Mladin R, et al.Esophageal perforation associated with cervical spine surgery: report of two cases and review of the literature. Dig Surg. 2004;21(3):246-249.

9. Dakwar E, Uribe JS, Padhya TA, et al.Management of delayed esophageal perforations after anterior cervical spinal surgery. J Neurosurg Spine. 2009;11(3):320-325. 